\title{
Principales figuras del Street Art en Galicia
}

\author{
Lorena ARÉvALO IGLESIAS \\ Universidad de Vigo \\ unodelsiete@gmail.com
}

\begin{abstract}
Resumen:
El presente trabajo pretende realizar un somero acercamiento a la figura de las/os principales artistas del panorama gallego actual de Street Art, por medio del análisis formal de sus obras y la puesta en relación de las mismas con el contexto social en el que se desarrollan, a fin de identificar los principales ejes de su discurso, considerando la vertiente más crítica y social de esta disciplina artística, cuyo estudio merece hoy un capítulo aparte en libros y cursos de historia del arte o comunicación.
\end{abstract}

Palabras clave: Graffiti; Contexto social; Crítica; Cultura urbana; Movilización.

\section{Street Art: art and activism in Galicia.}

\begin{abstract}
:
This paper aims to make an approach to the figure of the major artists of the current Galician Street Art, through formal analysis of his works and the linking of them with the social context in which they develop, to identify the main lines of his speech, considering the most critical aspect of this social and artistic discipline, whose study today deserves a separate chapter in books and art history courses or communication.
\end{abstract}

Key Words: Graffiti; Social Context; Review; Urban Culture; Mobilization.

\section{Referencia normalizada:}

Arévalo Iglesias, L. (2014): Principales figuras del Street Art en Galicia. Historia y Comunicación Social. Vol. 19. Núm. Especial Enero. Págs. 565-575.

Sumario: 1. Estado de la cuestión. 2. Metodología. 3. Artistas. 4. Análisis. 4.1. Ejes discurso visual. 4.2. Personajes. 4.3. Coherencia. 5. Conclusiones. 6. Referencias bibliográficas. 


\section{Estado de la cuestión}

Recientes corrientes historiográficas han aceptado la posibilidad de que la obra de arte (en cualquiera de sus manifestaciones, lo que hoy en día incluiría al arte urbano) pueda ser vista como un objeto de comunicación, al margen de su valor puramente estético, y entendiendo siempre a la obra de arte como el hecho sicial que es (Varela y Álvarez-Uría, 2008:XV). A este respecto, la crítica de arte ha adoptado dos enfoques metodológicos: la iconología (que centra este trabajo) y, en menor medida, la semiótica (centrada en el análisis exhaustivo de la estructura semántica a través de la articulación de diferentes signos estéticos, por lo que, aunque se trata de una perspectiva interesante, escapa a la intencionalidad de este trabajo). Edwin Panofsky (1972) , principal ideólogo del método iconográfico-iconológico, sostenía que existen tres niveles de profundización que permiten realizar un análisis completo de la obra: el primario (basado en las formas puras o los motivos artísticos), el secundario (de mayor complejidad, característico del lenguaje artístico) y el último, considerado de significado intrínseco, cuya percepción sólo es posible, según Panofsky, "cuando indagamos aquellos supuestos que revelan la actitud básica de una nación, un período, una clase, una creencia religiosa o filosófica". Esta visión es precisamente la que justifica la aplicación del método iconográfico-iconológico al análisis del arte urbano.

Así, según los principios del análisis iconográfico-iconológico, ciertas imágenes representadas a lo largo de la historia del arte surgen en un contexto histórico o social que deja su impronta en dicha obra. Para Panofsky, ninguna obra de arte puede ser analizada con independencia de su contexto, pues es de vital importancia para comprender su verdadero significado el conocer los valores simbólicos que encierra. Con Panofsky, por tanto, la obra de arte comenzó a ser estudiada en relación a su contexto, superando así el análisis meramente estético o figurativo que se venía realizando hasta entonces. Para este estudioso, toda representación artística podía expresar valores simbólicos particulares, por lo que era necesario encontrar un medio que permitiera al historiador del arte comprender el significado intrínseco de la obra, que revelaría, sin duda, la actitud, pensamiento, costumbres, maneras, etc. de la sociedad, periodo histórico o cultura en la que esta obra se enmarcaba. Así, el análisis iconográfico-iconológico, cuyas fases se describirán más adelante en este trabajo, permite identificar y clasificar la imagen que se estudia, los cambios que se han introducido en el tiempo y su origen.

Esta relación entre obra y contexto se hace especialmente patente en el Street Art, una disciplina que, por su misma naturaleza, representa la necesidad innata del ciudadano anónimo de expresarse públicamente acerca de la realidad, sea ésta política, económica, ideológica, etc., , dándose una arte y ámbito social (Brihuega, 2002: 145) conviertiendo al Street Art en un indicador histórico, un termómetro que permite medir la salud democrática de una sociedad. En palabras de Johannes Stahl (2009: 8):

Los símbolos que vemos en la calle y en las paredes no están en ningún caso desvinculados del tiempo que les corresponde. Ya sea acerca de las ideas políticas, de lo que se entiende como estético o de los objetivos que se persiguen en el momento, 
estos símbolos nos dan a menudo una clave, antes de que aquello que representan sen convierta en bien común de la cultura oficial.

\section{Metodología}

En primer lugar, se ha procedido a la realización de entrevistas en profundidad con las/os principales artistas, así como con los promotores de los principales festivales y espacios de difusión del arte urbano en Galicia, lo que permitió profundizar en la situación del Street Art en Galicia (promoción, difusión, perspectivas) y conocer, de primera mano, los orígenes, preocupaciones y proyectos de la/os artistas. De esta forma ha sido posible verificar, con el posterior análisis de las obras, si las inquietudes que las/os artistas evidenciaban en su discurso verbal se correspondían con las mostradas en su discurso visual, es decir, si había una coherencia entre ambas manifestaciones. Además, estas entrevistas permitieron, en un proceso no exento de un cierto grado de subjetividad, identificar a las principales figuras de esta disciplina por medio de la encuesta directa a estas/os mismas/os artistas, a fin de seleccionar sólo a aquellas/os que sus propias/os compañeras/os considerasen más destacables. Finalmente, la/os creadora/es seleccionada/os fueron Liqen, Peri, Sokram, Mou, Nana, Nash! y Xpen.

Así, en segundo lugar se procedió al análisis de las obras (es necesario aclarar que se ha procedido al análisis de la producción muralística de estas/os autoras/es, ignorando la producción realizada en otras disciplinas como la ilustración, el grabado, la escultura o la estampación), identificando los aspectos iconográficos e iconológicos de las figuras representadas en las piezas seleccionadas, dividiendo las imágenes en unidades mínimas dotadas de significado (análisis de aspectos semánticos individuales) para después poner nuevamente en relación cada una de estas unidades con el resto, con la intención de extraer su significado global. Asociando cada unidad semántica con su contexto concreto es posible comprobar si, en este marco particular, el significado atribuible a esa unidad responde a criterios universales (fácilmente identificables por un número elevado de culturas), o específicos (sólo comprensibles por personas cercanas a ese entorno social o momento histórico). Se hace necesario, por tanto, analizar esa cantidad de información con un método que, de forma global, permita realizar una lectura interpretativa basada en aspectos objetivos que vayan más allá de la mera especulación, de ahí la elección del método iconográfico-iconológico de Edwin Panofsky, que se ha completado con categorías identificadas por la Teoría general de la imagen. A continuación se desarrollan las fases de las que consta esta segunda parte del estudio.

\subsection{Descripción preiconográfica}

Análisis de las obras comprendidas como expresión estilística (más que significativa o simbólica). Por tanto, investigación contextual (hermenéutica). Si bien el 
método planteado por Panofsky propone ubicar la obra en un periodo artístico en base a las formas o técnicas que están presentes (aunque también contempla, en algunos casos, la necesidad de realizar un examen más riguroso que incluya el periodo y la cultura en la que ésta se lleva a cabo), en este caso esta contextualización se realizará en base a su marco social, cultural y político. La descripción preiconográfica de las obras comprende los siguientes aspectos: análisis histórico/cultural, análisis económico-político, análisis sociológico o antropológico, análisis psicológico/autorial y análisis comunicológico. Esta primera fase permite el análisis de las unidades de contexto: análisis del medio físico en el que se insertan las obras, análisis del medio geográfico y político en el que se insertan las obras y análisis del medio social en el que se insertan las obras.

\subsection{Análisis iconográfico}

En esta fase se procede a la identificación de imágenes, historias y alegorías, es decir, a la identificación y análisis de las distintas unidades semánticas que componen la pieza. Implica, por tanto, la investigación textual (semiótica). El análisis iconográfico implica un método meramente descriptivo, no interpretativo, y se ocupa de la identificación, descripción y clasificación de las imágenes. En este punto se hace necesario recurrir a la Teoría general de la imagen para proceder a un análisis más exhaustivo. Se trata de un proceso analítico objetivo que descontextualiza la imagen. La Teoría general de la imagen contempla tres niveles de análisis: lectura de la imagen, definición estructural y análisis plástico.

\subsection{Análisis iconológico}

Verdadero objetivo del análisis de la obra de arte, dilucidar la significación intrínseca o contenido. Se debe prestar atención a los procedimientos técnicos, a los rasgos de estilo y a las estructuras de composición tanto como a los temas iconográficos. Esta tercera fase permitirá la puesta en relación de imagen (unidades de registro) y entorno (unidades de contexto), mediante la identificación de referentes socio-culturales, la dotación de significados a los signos y, por tanto, de intencionalidad de la imagen (recodificación) y la interpretación (en base a todo lo anterior).

\section{Artistas}

\subsection{Liquen}

Vigo, 1980. Uno de los grandes nombres del arte urbano español, cuyas obras, cercanas al surrealismo, son predominantemente figurativas, a pesar de esconder un mensaje que va siempre mucho más allá de lo visible. Liqen y su hermano gemelo, el también artista urbano (y habitual del Desordes Creativas) Pelucas, comenzaron a dibujar, como sus compañeros, siendo niños. Liqen comenzó imitando piezas e 
ilustraciones que llamaban su atención, para poco a poco ir fijando su atención en aquello que lo rodeaba, la naturaleza. El blog mexicano NFG ha llegado a decir de su obra que "sus murales nos sumergen en un universo personal, de formas infinitas, transformando inconscientemente la realidad en la que vive, para que pueda ser absorbida y utilizada libremente, en un proceso de asimilación... la ciencia ficción, la fantasía, la cotidianidad, metamorfosis, la naturaleza, lo relacionado con el cosmos, la reinvención mitológica, son algunas constantes y variables que aparecen inconscientemente en su trabajo". Su arte ha traspasado fronteras, no sólo gallegas, sino también nacionales, llegando hasta México. Sus obras han sido expuestas en la galería ARTHOBLER.

\subsection{Peri}

Vigo, 1983. Artista polifacético, ilustrador y artista urbano. Esmalte, acrílico, tinta, rotulador o pintura plástica son algunos de los materiales con los que crea obras en casi cualquier superficie (mural, cartón, madera, lienzo, papel, tela...). Como Nana, Peri ha trasladado sus diseños al mundo del textil, creando junto a su compañero Xori la marca de camisetas Malaire. Peri define su obra como "pintura antiurbana", tal vez porque es precisamente el entorno urbano (gris, frío, yermo) uno de los blancos de sus críticas, como contraposición al mundo de la naturaleza, orgánico y vivo, que el artista defiende con cada una de sus obras, vehículo de transmisión de los valores ecológicos que el artista tiene tan presentes. Sus obras, siempre con este trasfondo crítico y reflexivo, están marcadas por la simbología, muy personal, del autor, lo que las hace inconfundibles. Peri ha participado en exposiciones como Portal 48, la organizada por Croa Magazine con motivo de su aniversario. Sus obras han sido publicadas en Croa Magazine o el Fanzine de Seara Records, entre otros.

\subsection{Sokram}

Ferrol, 1980. Vocalista y miembro del colectivo hip hop Dios ke te Crew e integrante de la pioneira crew de graffiti gallega Vandals (además de Colectivo Mutante), tomó contacto con el mundo del hip hop y el arte urbano en los años 90 . Sus primeras incursiones fueron tags, tipografías y pequeñas figuras en las calles de Ordes, Santiago y A Coruña. Como Mou, estudió Gráfica Publicitaria en la Escuela Superior de Arte y Diseño Pablo Picasso de A Coruña, y posteriormente, Fotografía Artística en la Escuela Superior de Arte y Diseño Mestre Mateo de Santiago de Compostela. Sokram completó su formación con diversos cursos, lo que amplió sus perspectivas y posibilidades técnicas (spray, plástica, stencil o poster, entre otras técnicas con las que embellece y dota de mensajes a muros, fachadas, mobiliario urbano o naturaleza inerte). En el CV de Sokram destaca la participación eventos como el Intercontracultura (Porriño, Pontevedra), el Compostela Skate (Santiago), el UrbanX Festival (Vigo), El graffiti más ancho de él mundo (Madrid), el VGA Festival (Vilagarcía de Arousa, Pontevedra), el Festival de Arte Multimedia \& Música Avanzada "Elecktronica" (Pontevedra) o el MadPosterArt (Festival internacional de Poster Art de Madrid), además del Desordes Creativas o las exposiciones colectivas "Extruja 
Tour" (Tabacalera CSA, Madrid) o "Artistas Reincidentes", (CC Ordes). Su obra ha sido recogida en la revista INTEREA Visual, el fanzine Lana Llave.

\subsection{Mou}

Santiago de Compostela, 1981. Para Mou, el primer contacto con el graffiti llega en el año 1998, aunque su actividad en este ámbito cobra peso a partir del 2002, como miembro de Dios ke te Crew. Este hecho coincide en el tiempo con su entrada en la Escuela Superior de Arte y Diseño Pablo Picasso, en la que estudio Gráfica Públicitaria, lo que ampliará no sólo sus conocimientos, sino también su técnica y perspectivas. En este sentido, Mou se distingue de sus compañeros, al estar su obra especialmente influenciada por el diseño gráfico (así como el comic y la banda deseñada, estos sí, comunes a muchos de los artistas analizados). Como el propio colectivo indica, "estas influencias convergen en su trabajo en un universo de personajes donde priman los volúmenes planos y los rasgos limpios y definidos". Su "Buen hacer" lo ha llevado a participar en eventos como el Desordes Creativas, en todas sus ediciones, el Compostela Skate (Santiago de Compostela), el Festival Magas había Sido! (Poulo, A Coruña) o el Customize Sessions 1 (Cultura Urbana Shop, Santiago).

\subsection{Nana}

Santiago de Compostela, 1983. Aficionada al dibujo desde niña, comienza su formación en el mundo del arte estudiando Joyería Artística en la Escuela Superior de Arte y Diseño Mestre Mateo en Compostela. Su interés por el graffiti nace en el año 2006. Es entonces cuando comienza a trasladar su personal estética a las calles de Santiago de Compostela, Ordes, Madrid o A Coruña. Es en esta ciudad en la que realiza estudios de Ilustración, concretamente, en la Escuela Superior de Arte y Diseño Pablo Picasso. Participa en varias exhibiciones y festivales de arte urbana como MAD Poster Art (Festival Internacional de Poster Art de Madrid), la primera edición del Desordes Creativas (repetirá en las posteriores) o el Compostela Skate 2010. Nana traslada sus particulares diseños al mundo del textil, lo que la ha llevado a participar en el Customize Sessions 1 (Cultura Urbana Shop), o a crear su propia marca, Bicho Negro. El estilo gráfico de Nana se caracteriza por conjugar figuras, temas y colores aparentemente infantiles con mensajes impactantes.

\subsection{Nash!}

Rianxo, 1989. Su formación artística comienza de niño, etapa en la que asiste a clases de pintura, comic o dibujo. El hecho de conjugar distintas disciplinas desde muy pequeño ha permitido que este artista muestre un dominio evidente de diversas técnicas. Como Nana, comienza su andadura en el mundo del arte urbano en el año 2006, a su llegada a Santiago de Compostela. Poco después forma, junto con algunos compañeros la crew Comi2, muy activa en la zona de Compostela (y participante en la primera edición del Desordes Creativos). Posteriormente, estudia Ilustración en la Escuela Superior de Artes y Diseño Pablo Picasso de A Coruña. Este artista 
sigue diversificando las técnicas empleadas en sus obras, abarcando la ilustración, el comic, el graffiti, el stencil, la tipografía o el diseño gráfico. Nas!, como creador prolífico, ha dejado su huella a lo largo de estos años en ciudades como Vigo, Ordes, Santiago de Compostela, Madrid, A Coruña o Barcelona. Se trata, así, de un artista reconocido a nivel nacional, y su obra ha quedado recogida en publicaciones como la revista HipHopNation, o el libro "Los nombres esenciales del arte urbano y el graffiti español" (Editoria Luwnberg), obra de la que también forman parte las piezas de Nana,Mou y Sokram (como Colectivo Mutante) o Liqen.

\subsection{Xpen}

Vigo, 1978. Artista "procedente" del graffiti tradicional, su trabajo se ha ido ampliando a lo largo de los años, abarcando en la actualidad diversas disciplinas y estilos, incluyendo la ilustración, el diseño web, la animación o el muralismo, lo que aumenta la complejidad técnica y argumental de su obra, muy extensa. En la obra de XPEN destaca como elemento predominante el mundo de la tecnología, la industria y la robótica, por lo que sus piezas se tiñen de cierto posthumanismo apocalíptico, en representación de una sociedad que considera "alienada y mecanizada". Sus protagonistas son seres cuasi humanos, cuasi robóticos, cuyo lenguaje ininteligible, muchas veces en código binario, presagia en cambio de paradigma a nivel global. XPEN ha estado presente en eventos como el Festival de Graffiti Klonica (Narón, A Coruña), el Festival de Graffiti Intercontracultura de Porriño (Pontevedra) o el Festival de arte independiente y nuevas tendencias de Pontevedra IFI (Pontevedra), además del Desordes Creativas. A participado, además, en talleres y formaciones. 


\section{Análisis}

\subsection{Ejes del discurso visual}

Cuadro 1: Ejes del discurso visual

\begin{tabular}{|c|c|}
\hline ARTISTA & TEMAS CENTRALES, MENSAJE Y ESTILO \\
\hline LIQEN & $\begin{array}{l}\text { Destacan como temas centrales en la obra de Liquen la laturaleza, la mitologia, } \\
\text { los procesos de transformación (orgánica, social o personal), la espiritualidad y } \\
\text { su relación con la anatomia/morfologia. Su principal mensaje parece ser la } \\
\text { certeza de la mutación como destino inexorable y esencia misma del organismo } \\
\text { vivo. Para ello, se vale de un estilo figurativo, casi cercano al surrealismo. Las } \\
\text { figuras de Liquen se caracterizan por una tendencia a la deformación, que se } \\
\text { produce de forma progresiva. }\end{array}$ \\
\hline PERI & $\begin{array}{l}\text { Los temas centrales de la obra de Peri son la ecologia, la naturaleza, los } \\
\text { organismos vivos y la industrialización, así como los efectos de ésta en los } \\
\text { ámbitos anteriores. El artista lleva estos temas al entorno exterior del ser } \\
\text { humano, pero también al interior (liberación del "yo" autentico, natural). Su } \\
\text { mensaje se resume en un frase: “......solo tras mostrarnos como realmente somos } \\
\text { podremos llegar a ser libres...". Su estilo es cercano al simbolismo, con una } \\
\text { estética inconfundible a lo largo de toda su producción. A esto contribuye la } \\
\text { repetición de sus propios "seres", protagonistas de muchas de sus piezas. Estos } \\
\text { seres sustituyen a cualquier forma de vida humana o animal identificable. }\end{array}$ \\
\hline SOKRAM & $\begin{array}{l}\text { Centran la temática de su obra la cultura popular/urbana, la música (otra de sus } \\
\text { inquietudes artisticas), la libertad de expresión y, en cierta medida, la critica } \\
\text { antisistema. Su mensaje encierra una clara negativa al sometimiento, a silenciar } \\
\text { las voces disidentes, al status quo.Su estilo es figurativo, aunque con elementos } \\
\text { de fantasía. Su icono autorreferencial es el payaso, presente en muchas de sus } \\
\text { obras. }\end{array}$ \\
\hline MOU & $\begin{array}{l}\text { Como Sokram, compañero y socio en el colectivo Mutante Creativo, su obra } \\
\text { tiene claras referencias a la ultura popular/urbana y a la preocupación por el } \\
\text { medioambiente. Su lema podria ser "mutar para adaptarse". Su estilo es } \\
\text { figurativo. En palabras de Mario Suárez (2011: } 88 \text { ), la obra de Mou, como la de } \\
\text { Sokram, puede ser tildada de "canallesca". }\end{array}$ \\
\hline NANA & $\begin{array}{l}\text { Son temáticas recurrentes lo femenino, lo infantil, cultura urbana, fábulas. Su } \\
\text { obra representa, según las propias palabras de la artista, "Un viaje pintoresco en } \\
\text { el que monstruos, bichos y niñas con cuerpo de tinta y alma de color vienen a } \\
\text { jugar a nuestro mundo gris". Estilo claramente figurativo, fäcilmente } \\
\text { identificable. Como en el caso de Peri, sus personajes suelen repetirse. Estética } \\
\text { marcadamente näif. }\end{array}$ \\
\hline NAS! & $\begin{array}{l}\text { Su principal inspiración temática es la cultura urbana. Su mensaje se centra en } \\
\text { la improvisación y la independencia para mantenerse al margen del sistema. } \\
\text { Estilo figurativo. }\end{array}$ \\
\hline XPEN & $\begin{array}{l}\text { Su obra, fäcilmente identificable, tiene como temática central la tecnologia, la } \\
\text { robótica y la mecanización del ser humano. En su imaginario, el ser humano } \\
\text { está siendo corrompido y alienado en una sociedad en la que la máquina escala } \\
\text { posiciones. Su estilo es figurativo, con elementos futuristas, y una estética } \\
\text { cercana al posthumanismo. }\end{array}$ \\
\hline
\end{tabular}




\subsection{Protagonistas}

Cuadro 2: Protagonistas

\begin{tabular}{|c|c|}
\hline ARTISTA & PROTAGONISTAS DE LA OBRA \\
\hline LIQEN & $\begin{array}{l}\text { Los animales son los grandes protagonistas de la obra de Liqen. Sus actitudes } \\
\text { suelen completar el mensaje latente de las obras. También los seres humanos } \\
\text { (siempre personas anónimas en constante metamorfosis) ocupan un lugar } \\
\text { destacado. A pesar de (o precisamente por) su gran carga simbólica, las obras } \\
\text { de Liquen no suelen completarse con textos. }\end{array}$ \\
\hline PERI & $\begin{array}{l}\text { Resulta complicado identificar los agentes protagonistas de la obra de Peri, pues } \\
\text { suelen ser esos seres cargados de simbologia a los que ya nos hemos referido } \\
\text { (grandes entes formados por ramas de árbol, con una careta por cara) los que } \\
\text { centra toda la atención. Éstos están siempre acompañados por una serie de } \\
\text { elementos fácilmente reconocibles (pirámides, pájaros, casas, planetas...) cuyo } \\
\text { papel en la composición escapa al evidente. No se identifican seres humanos, } \\
\text { salvo algunas excepciones. La obra de Peri no incluye texto. }\end{array}$ \\
\hline SOKRAM & $\begin{array}{l}\text { Los seres humanos protagonizan las obras de Sokram, en ocasiones pobladas } \\
\text { también de objetos dotados de personalidad humana por medio de actitudes o } \\
\text { atributos fisicos (casettes, máquinas de tren, piedras...). Los perfiles plasmados } \\
\text { por Sokram pertenecen al mundo adulto.Los animales son muy habituales. } \\
\text { Suelen representar actitudes o realidades negativas, nocivas o malignas. } \\
\text { Siempre encierran un mensaje, y la elección de un animal u otro nunca es } \\
\text { arbitraria. También el texto es relativamente habitual en la obra de este artista, } \\
\text { si bien suele acompañar a imágenes carentes de finalidad crítica, más cercanas } \\
\text { al entretenimiento o la cultura popular. }\end{array}$ \\
\hline MOU & $\begin{array}{l}\text { Sus obras suelen ser autorreferenciales, por lo que la figura humana ocupa un } \\
\text { lugar destacado. También los animales protagonizan algunas de sus obras. } \\
\text { Algunas piezas de Mou contiene texto, pero éste no tiene finalidad critica. }\end{array}$ \\
\hline NANA & $\begin{array}{l}\text { Distintas "versiones" de una misma chica/niña (que bien podria ser la propia } \\
\text { Nana) protagonizan sus obras. Dados los rasgos caracteristicos de estas figuras, } \\
\text { estas protagonistas podrian ser también consideradas como niñas en } \\
\text { determinadas obras. Las protagonistas de Nana suelen estar acompañadas por } \\
\text { varios animales (el más habitual es un perro del que estas figuras infantiles no } \\
\text { suelen separarse, y que representa a la mascota de la artista, Montana). No es } \\
\text { habitual encontrar mensajes verbales en la obra de Nana. }\end{array}$ \\
\hline NAS! & $\begin{array}{l}\text { Los seres humanos son protagonistas de casi todas las obras. En cuanto a los } \\
\text { animales, no se identifican, habitualmente, si bien en uno de los ejemplos } \\
\text { analizados es un animal el que simboliza al sistema, con todo lo malo que } \\
\text { implica. }\end{array}$ \\
\hline XPEN & $\begin{array}{l}\text { Protagonizan sus obras, aunque generalmente se trata de humanos } \\
\text { "evolucionados" o cyborgs, mitad orgánicos, mitad mecánicos. No se identifica } \\
\text { texto en la obra de Xpen, al margen de algún tag del que el artosta se sirve para } \\
\text { complementar la pieza. (tal vez algún tag que complementa la obra). }\end{array}$ \\
\hline
\end{tabular}


4.3. Coherencia

Cuadro 3: Coherencia

\begin{tabular}{|l|l|}
\hline ARTISTA & COHERENCIA DEL DISCURSO \\
\hline LIQEN & $\begin{array}{l}\text { La obra de Liqen presenta unas premisas comunes desde sus inicios. Estas se } \\
\text { han mantenido a lo largo de los años, independientemente del entorno en el que } \\
\text { se ubique la obra, o incluso de la disciplina en la que se realiza la misma } \\
\text { (fotografia, ilustración, graffiti...). }\end{array}$ \\
\hline PERI & $\begin{array}{l}\text { Como en el caso de Liqen, las caracteristicas visuales (estilísticas) y narrativas } \\
\text { de su obra se mantienen a lo largo del tiempo. Las inquietudes que el artista } \\
\text { refleja en sus piezas se repiten. }\end{array}$ \\
\hline SOKRAM & $\begin{array}{l}\text { La obra de Sokram se caracteriza por su multidisciplinariedad y versatilidad. } \\
\text { Este artista crea imágenes muy distintas entre si, tanto en cuanto a su estilo } \\
\text { visual y técnica como en cuanto a su temática, en función del contexto en el que } \\
\text { desarrolla la pieza. Asi, no existe una coherencia evidente en su discurso global, } \\
\text { si bien sus preocupaciones e intereses se plasman en las obras de contenido } \\
\text { social. }\end{array}$ \\
\hline MOU & $\begin{array}{l}\text { Como en el caso de Sokram, la obra de Mou es diversa y diferenciada entre si } \\
\text { en técnica, estilo y temática. }\end{array}$ \\
\hline NANA & $\begin{array}{l}\text { La obra de muestra una coherencia visual absoluta desde los inicios de su } \\
\text { carrera (es imposible no identificar una pieza suya), si bien su discurso se ve } \\
\text { modificado en cada una de sus obras. El denominador común es el contraste } \\
\text { entre la aparente inocencia de las figuras y la realidad del mensaje que } \\
\text { esconden, siempre más adulto, y en ocasiones, critico. }\end{array}$ \\
\hline NAS! & $\begin{array}{l}\text { La obra de Nas!, como su técnica, es totalmente cambiante e independiente en } \\
\text { cuanto a estilo y lineas narrativas. }\end{array}$ \\
\hline XPEN & $\begin{array}{l}\text { Xpen presenta unidad estilistica en toda su obra. También en cuanto al discurso, } \\
\text { queda patente que sus preocupaciones e intereses se mantienen a lo largo del } \\
\text { tiempo. }\end{array}$ \\
\hline
\end{tabular}

\section{Conclusiones}

En líneas generales, podríamos afirmar que son tres los grandes temas que centran el trabajo de la/os autora/es analizada/os: la crítica al poder establecido (económico, político, social), la preocupación por la deriva "psicológica" del ser humano en una sociedad que consideran individualista y alienante y las referencias a la cultura urbana y popular gallega. Si bien resulta complejo extraer un mensaje global que pueda recoger lo transmitido por as/os artistas, cabría proponer la idea de la mutación, la adaptación y la desobediencia como claves necesarias y poderosas para resistir en la sociedad actual. En su discurso tanto verbal como visual ocupa un lugar importante la desobediencia civil (aunque moderada y centrada en su ámbito de trabajo).

El estilo elegido por la/os artistas es predominantemente figurativo, si bien todas las obras encierran un significado oculto (en ocasiones muy complejo, debido a la simbología particular del artista). 
Si nos detenemos en el análisis de protagonistas, comprobamos que son personas anónimas las que protagonizan la mayoría de las obras (en una línea, dentro del arte urbano de corte crítico, más cercana a la escogida por artistas actuales como Banksy o Fairey, en contraposición a una de las colecciones de murales de contenido social más célebres de Europa, los murales de Belfast, protagonizados en buena medida por figuras reconocibles del mundo de la política, la cultura o el deporte). Resulta también destacable la presencia de figuras animales, protagonistas o co-protagonistas, junto a las personas, de muchas de las obras. La aparición de un animal nunca es arbitraria, y éste siempre encierra una simbología clara, o se utiliza como metáfora de la sociedad. Las/os artistas analizados no suelen recurrir al texto en sus obras, por lo que la carga simbólica descansa fundamentalmente en la ilustración.

En relación al análisis de coherencia, la/os autoras/es se dividen en dos grandes grupos. Aquellos cuyos temas centrales se mantienen a lo largo del tiempo, y son reflejo de sus preocupaciones cuasi filosóficas, derivada de la reflexión profunda (Liquen, Peri, Xpen, Ericailcane), y aquellos cuya obra presenta diversidad estilística o temática (Sokram, Mou, Nana, Nas!).

\section{Bibliografía}

BRIHUEGA, J. (2002). "Arte y sociedad. Genealogía de un parámetro fundamental". En BOZAL, Valeriano (Ed.): Historia de las ideas estéticas y de las teorías artísticas contemporáneas. Vol. II. Madrid: A. Machado Libros. p. 145

PANOFSKY, E. (1972): Estudios sobre iconología. Madrid: Alianza.

SUÁREZ, M. (2011). Los nombres esenciales del arte urbano y del graffiti español. Madrid: Lumwerg.

STAHL, J. (2009): Street Art. Postdam: H.F.Ullmann.

VARELA, Julia y ÁLVAREZ-URÍA, Fernando (2008): Materiales de sociología del arte. Madrid: Siglo XXI.

\section{La autora}

Lorena Arévalo Iglesias es Licenciada en Publicidad y RRPP por la Universidad Pontificia de Salamanca, Especialista en Arte Contemporáneo por el Instituto Superior de Arte de Madrid, Máster en Cooperación Internacional por la Universidad de Santiago de Compostela y Máster en Investigación en Comunicación por la Universidad de Vigo. Alumna del Programa de Doctorado en Comunicación de la Uvigo, desarrolla su labor como investigadora en formación en el Departamento de Psicología Evolutiva y Comunicación de la misma universidad. Su trayectoria profesional en el ámbito privado se mueve entre la creatividad publicitaria y la gestión de comunicación para entidades sociales. 